\title{
Eating location trends in a representative sample of Irish adults
}

\author{
D. M. Martyn ${ }^{1}$, B. A. McNulty ${ }^{1}$, J. Walton ${ }^{2}$, A. Flynn ${ }^{2}$, A. P. Nugent ${ }^{1}$ and M. J. Gibney ${ }^{1}$ \\ ${ }^{1}$ UCD Institute of Food and Health, University College Dublin, Belfield, Dublin 4, Ireland and ${ }^{2}$ School of Food and \\ Nutritional Sciences, University College Cork, Ireland
}

Previous research examined the influence of eating location on the diets of Irish children, with poorer nutrient intake being associated with food consumed outside of the home ${ }^{(1)}$. Using data from the National Adult Nutrition Survey (NANS) ${ }^{(2)}$, the aim of the present study was to characterise the eating locations where Irish adults consume food and beverages, and the extent to which the various locations contribute to dietary energy intake. During the NANS, participants recorded all food and beverages consumed during a 4-d period using a semi-weighed food diary. For each eating occasion, participants were asked to record the location where the food was prepared and this was subsequently coded by the fieldworker as the 'eating location'. For example, if a sandwich was prepared at home but consumed at work, this was recorded as 'home'; however, if a sandwich was prepared and consumed in work, this was coded as 'work'. There were 133068 eating occasions in the NANS dataset, from which seventeen different eating location categories were identified. Data analysis was carried out using PASW Statistics 18.

\begin{tabular}{|c|c|c|c|c|c|c|c|c|}
\hline & \multirow[b]{2}{*}{$n$} & \multirow[b]{2}{*}{$\%$ Consumers } & \multirow[b]{2}{*}{$\begin{array}{l}\text { Mean number of } \\
\text { eating occasions* }\end{array}$} & \multirow[b]{2}{*}{$(\mathrm{SD})^{*}$} & \multirow[b]{2}{*}{$\begin{array}{c}\% \text { of eating } \\
\text { occasions }\end{array}$} & \multirow[b]{2}{*}{$\begin{array}{c}\% \text { of eating occasions } \\
\text { outside the home }\end{array}$} & \multicolumn{2}{|c|}{$\%$ Contribution to energy } \\
\hline & & & & & & & $\begin{array}{c}\text { Total } \\
\text { population }\end{array}$ & $\begin{array}{c}\text { Consumers } \\
\text { only }\end{array}$ \\
\hline Home & 1499 & 99.9 & 14.1 & $(5.2)$ & 78.0 & & 74.2 & 74.2 \\
\hline Other home & 383 & 25.5 & 1.9 & (1.7) & 2.9 & & 3.2 & 11.8 \\
\hline Outside home & 1196 & 79.7 & 4.6 & (3.4) & 19.0 & & 22.6 & 27.3 \\
\hline Work & 533 & 35.5 & 3.6 & $(2.7)$ & 6.1 & 32.2 & 2.1 & 19.1 \\
\hline Takeaway & 370 & 24.7 & 1.3 & $(0.6)$ & 1.5 & 7.7 & 8.2 & 7.4 \\
\hline Restaurant & 806 & 53.7 & 2.2 & $(1.8)$ & 7.3 & 38.2 & 2 & 14.4 \\
\hline Shop & 359 & 23.9 & 1.8 & $(1.2)$ & 1.6 & 8.3 & 3.3 & 7.6 \\
\hline Other out & 403 & 26.9 & 1.7 & $(1.2)$ & 2.6 & 13.6 & 7 & 11.5 \\
\hline
\end{tabular}

*Values calculated for 4 day period ( $64.1 \%$ weekdays, $39.1 \%$ weekend days for all data collected).

The majority of meals consumed by Irish adults were prepared at home ( $78 \%$ of all eating occasions); however, a large proportion of the population ate at least one meal outside the home (79.7\% consumers or $19 \%$ of all eating occasions). Restaurants (7.3\%) and work $(6.1 \%)$ were the most common eating places outside of the home. Among those people who ate 'outside of the home', food and drink eaten at work contributed the highest percentage to dietary energy $(19.1 \%)$, followed by food consumed in restaurants (14.4\%).

This data suggests that the home should be the main focus for anti-obesity campaigns in Irish adults; however, workplaces and restaurants should also be considered. Further work will be completed to explore the macro- and micronutrient intakes at each location.

This study was funded by the Irish Department of Agriculture, Fisheries and Food under the Food for Health Research Initiative (2007-2012).

1. Burke SJ et al. (2007) Public Health Nutr 10, 599-607.

2. Irish Universities Nutrition Alliance (2011) National Adult Nutrition Survey. http://www.iuna.net/. 